\title{
Reduce, reuse, recycle: good stewardship of research data
}

\author{
Marcel Dijkers ${ }^{1}$
}

Received: 15 January 2019 / Accepted: 15 January 2019 / Published online: 5 February 2019

(c) International Spinal Cord Society 2019

The well-known international recycling logo sometimes is accompanied by the phrase "Reduce, reuse, recycle", which expresses that we should reduce our consumption of nonrenewable resources (such as oil), re-use products (such as shopping bags made with plastic obtained from oil), and recycle when their useful life has ended, to be reborn as new products (such as plastic park benches). How does this apply to research data?

In terms of reduce: in the last two decades, concerns have increasingly been expressed that the biomedical research "industrial complex" is tremendously wasteful [1]. We start research without first doing a careful analysis (e.g. using a systematic review) whether the research question still needs to be answered. We create research designs that are inadequate to answer our question, because our sample is too small, or key outcomes are not collected, or we allow attrition of subjects to such a degree that a randomized controlled trial degenerates into a non-controlled study of a selective sample. Sometimes the problem of waste is that we have a sample that is too large, or we collect too many outcomes, or collect them too often. Then, when we report the findings, we produce, using incorrect analytical methods, articles that selectively report outcomes, are inadequate to help readers understand the results of our research, or do not allow translation of the findings into clinical practice [2].

Awareness of the need to reduce research quantities and improve what remains is growing, and various individual researchers, journals, funding agencies and others have developed initiatives to spend always-limited research funds more parsimoniously. However, we are still far from a comprehensive solution to the waste of resources that Altman in 1994 called a scandal [3].

Marcel Dijkers

marcellinus.P.dijkers@ wayne.edu

1 Wayne State University, Department of Physical Medicine and Rehabilitation, Detroit MI, USA
Reuse of data addresses the issue that sometimes researchers can use their data again. Reference here is not to (semi-)duplicate publication, where the same results are rehashed many times, but serendipity: researchers, thinking about the next research project or reading someone else's paper, realize that their existing data might be useful in shining some (preliminary) light on a new question.

Recycle in this context is not much different from Reuse, but is used to designate making one's data available to other researchers for use in secondary analysis, individual patient data meta-analysis, reanalysis to check on the findings reported by the data creator, or for any other valid scientific purpose. More and more funding agencies, professional organizations, journals, and publishers now endorse Open Data-making 'raw' data available to researchers, clinicians and patients worldwide, with no or very limited restrictions as to what should be available when, to whom and how. Spinal Cord and its publisher, Springer Nature, and partner, the International Spinal Cord Society, all support this initiative, which is expressed in the journal's Research Data Policy as follows:

We strongly encourage that all datasets on which the conclusions of the paper rely should be available to readers. We encourage authors to ensure that their datasets are either deposited in publicly available repositories (where available and appropriate) or presented in the main manuscript or additional supporting files whenever possible. If a public repository does not exist, the information must be made available to editors and referees at submission and to readers promptly upon request. Any restrictions on material availability or other relevant information must be disclosed in the manuscript's Methods section and should include details of how materials and information may be obtained.

In a 2016 editorial, I called attention to the "moral obligation" of Spinal Cord authors to share their data [4], and provided a tally for the year 2015: of 144 primary 
quantitative studies, just one made a statement (however inadequate) on data availability. All 143 others either claimed "There were no data to deposit" or did not address the issue at all. Recently, I analyzed all papers published in 2016-2018, and things have not improved: of 435 primary quantitative studies published by Spinal Cord, $95 \%$ claimed that there were no data to deposit, or made no statement.

Spinal Cord is committed to increasing data sharing. Now, when submitting their review, peer reviewers are asked to reflect on this issue and respond to the following question:

Do the authors address data availability?

This reminds peer reviewers and thus the authors that sharing of data with researchers, clinicians, study participants, and patients is an obligation. This approach is likely to be effective: all improvement over 2015 came in 2018, when this question was introduced. Spinal Cord now also makes it clear in its decision letters that suitability for publication will be influenced by authors' willingness to share data. This issue of Spinal Cord contains an article addressing in detail the why and how of making one's data available, without infringing on the rights of privacy and confidentiality of research participants and patients [5]. It is hoped that over 2019 and 2020 we will see a further improvement in authors' willingness to embrace this important initiative.

\section{Compliance with ethical standards}

Conflict of interest The author declares that he has no conflict of interest.

Publisher's note: Springer Nature remains neutral with regard to jurisdictional claims in published maps and institutional affiliations.

\section{References}

1. Glasziou P, Chalmers I. Research waste is still a scandal-an essay by Paul Glasziou and Iain Chalmers. Br. Med. J. 2018;363: $\mathrm{k} 4645$.

2. Glasziou P, Altman DG, Bossuyt P, Boutron I, Clarke M, Julious S, et al. Reducing waste from incomplete or unusable reports of biomedical research. Lancet. 2014;383:267-76.

3. Altman DG. The scandal of poor medical research. Br. Med. J. 1994;308:283-4.

4. Dijkers MP. Spinal Cord authors have a moral obligation to share their data. Spinal Cord. 2016;54:165.

5. Dijkers MP. A beginner's guide to data stewardship and data sharing. Spinal Cord. 2019. https://doi.org/10.1038/s41393-0180232-6. 